\title{
Correction to: Major and trace elements in water from different sources in Jeddah City, KSA
}

Eid I. Brima ${ }^{1} \cdot$ Hassan M. AlBishri ${ }^{2}$

Published online: 11 November 2017

(C) Saudi Society for Geosciences 2017

\section{Correction to: Arab J Geosci (2017) 10:436 \\ https://doi.org/10.1007/s12517-017-3221-8}

The original version of this article, unfortunately, contained errors.

Figure $1 \mathrm{~b}$ has appeared in the published PDF of the article. But reference "Makkahrp (2017)" was deleted from the caption and in the list of references. The deleted reference is specifically for the Fig. $1 b$.

\section{References}

Makkahrp (2017) A development and activation project of the regional plan for Makkah Almukaramah Region. http://www. makkahrp.gov.sa/makkahrp/governrates/gov_1_jeddah.html. Accessed 11 Sept 2017

SGS (2017) Sedimentary rocks. http://www.sgs.org.sa/English/Geology/ Phanerozoic/Pages/default.aspx. Accessed 30 Sept 2017

The online version of the original article can be found at https://oi.org/ 10.1007/s12517-017-3221-8.

Eid I. Brima

ebrahim65@gmail.com

1 Department of Chemistry, Faculty of Science, King Khalid University, P.O. Box 9004, Abha 61413, Saudi Arabia

2 Department of Chemistry, Faculty of Science, King Abdulaziz University, Jeddah, Saudi Arabia 
Fig. 1 Simplified geological map of Saudi Arabia including Jeddah highlighted. a SGS (2017)

(Modified from http://www.sgs. org.sa/English/Geology/

Phanerozoic/Pages/default.aspx). b Geological map of Jeddah (modified from source: Regional Plan for Makkah Almukaramah Region 1430H). Makkahrp (2017). Website: http://www. makkahrp.gov.sa/makkahrp/ governrates/gov_1_jeddah.html
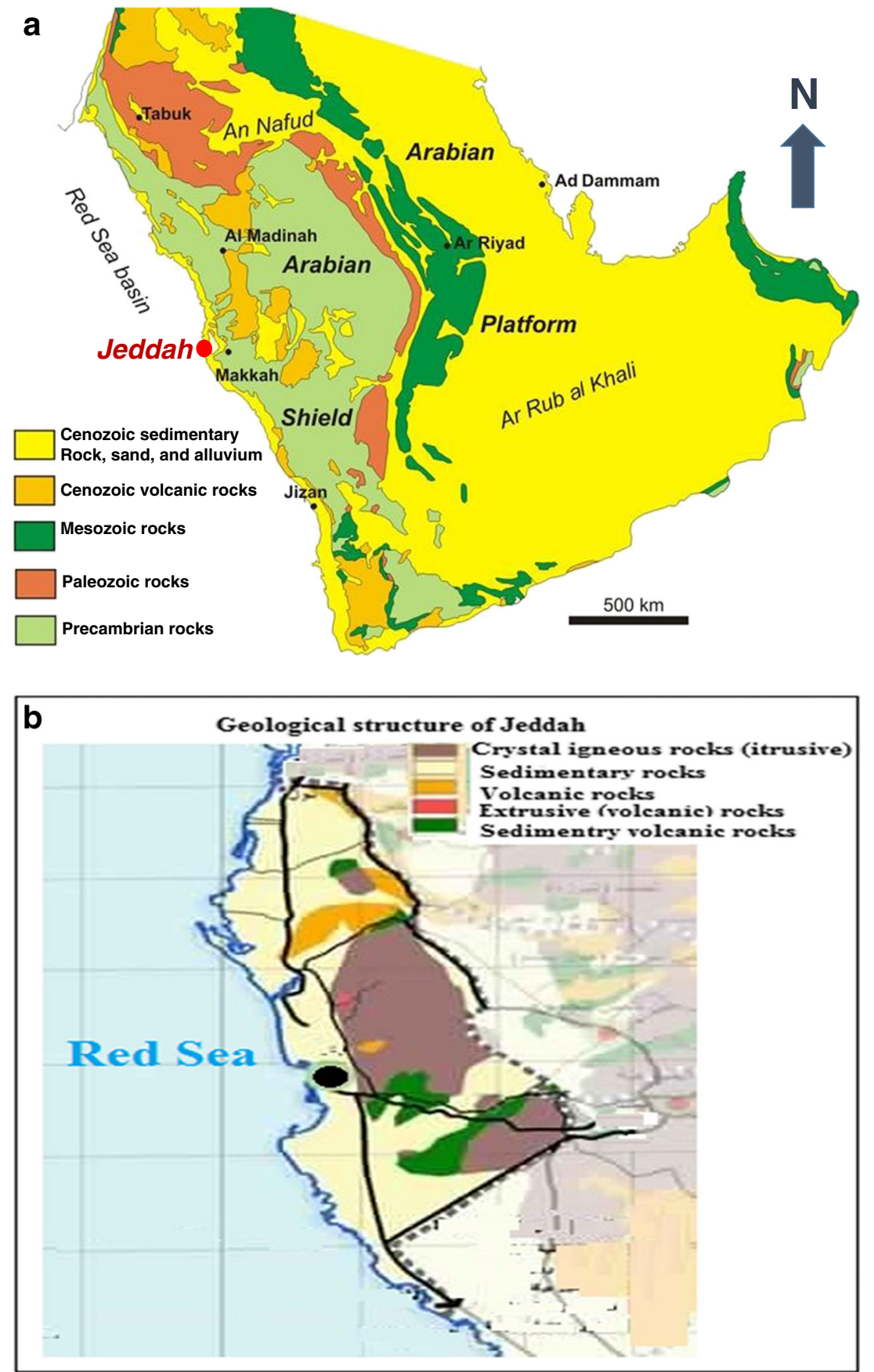